\title{
ResearchOnline@JCU
}

This is the author-created version of the following work:

Bellwood, David R., Hemingson, Christopher R., and Tebbett, Sterling B. (2020)

Subconscious biases in coral reef fish studies. BioScience, 70 (7) pp. 621-627.

Access to this file is available from:

https://researchonline.jcu.edu.au/66790/

(C) The Author(s) 2020. Published by Oxford University Press on behalf of the American Institute of Biological Sciences.

Please refer to the original source for the final version of this work: 


\section{Subconscious Biases in Coral Reef Fish Studies}

2

3 David R. Bellwood*, Christopher R. Hemingson, Sterling B. Tebbett
4

5

ARC Centre of Excellence for Coral Reef Studies; and College of Science and Engineering, James Cook University, Townsville, Queensland 4811, Australia

${ }^{*}$ Corresponding Author:

Email: david.bellwood@jcu.edu.au

\section{Abstract}

In complex, diverse ecosystems, one is faced with an exceptionally challenging decision: which species to examine first, and why? This raises the question: is there evidence of subconscious biases in study species selection? Likewise, in selecting methods, locations and times? We addressed these questions by surveying the literature on the most diverse group of vertebrates (fishes) in an iconic high-diversity ecosystem (coral reefs). The evidence suggests that we select study species that are predominantly yellow. Reef fish studies also selectively examine fishes that are behaviourally bold, and in warm, calm, attractive locations. Our findings call for a re-evaluation of study species selection, and methodological approaches, recognising the potential for subconscious biases to drive selection for species that are attractive rather than important, and methods that give only a partial view of ecosystems. Given the challenges faced by high diversity ecosystems, we may need to question our decision-making processes.

\section{Keywords}

Biodiversity; Coral reef; Fish; Function; Subconscious bias 
Coral reefs are one of the world's most iconic high-diversity ecosystems. Such diversity offers a plethora of potential study species, leaving one faced with an exceptionally challenging decision: which species do we examine first? And where, when and how should we conduct our study? Logically, it is in such high-diversity systems that the potential for subconscious biases are likely to be greatest, given the range of study options available (Bonnet et al. 2002; Clark and May 2002). This issue is particularly pressing as many highdiversity ecosystems are rapidly reconfiguring in response to climate-induced environmental disruption (Barlow et al. 2018; França et al. 2020). As a result, there have been urgent calls to understand and maintain the ecosystem functions that sustain high-diversity ecosystems, such as coral reefs, and the services they provide to humanity (Hughes et al. 2017; Brandl et al. 2019b). However, our understanding of ecosystem functions depends on the species we examine and how we study them (Bellwood et al. 2019). Such selection processes may involve subconscious biases.

There is a burgeoning literature on the extent, nature and impacts of subconscious biases (also termed unconscious and, perhaps most accurately, implicit biases) (e.g. McNutt 2016; Knezek 2017; Asplund and Welle 2018; Baum and Martin 2018). These biases have been repeatedly shown to influence the nature of academia, especially in terms of selecting researchers for funding, promotion and publication (Wenneras and Wold 1997; Bornmann et al. 2007; Moss-Racusin et al. 2012). However, there have been few critical evaluations of our decisions when undertaking scientific research, especially in terms of what species we study (but see Bonnet et al. 2002; Clark and May 2002), or how we conduct our research. To address this knowledge gap we asked two key questions: 1) is there evidence of biases in our selection of study species and, 2) are there biases in our approaches when undertaking research in high-diversity systems? Ultimately, this raises the question: to what extent may these biases shape our understanding of ecosystem processes?

To address these questions, we surveyed the published literature on the most diverse group of vertebrates (fishes) in an iconic high-diversity ecosystem (coral reefs) (Fig. 1). Coral reef fishes represented a particularly amenable study group because of their ease of identification to a species level, taxonomic stability, pantropical distribution, and exceptional taxonomic and morphological diversity (Fig. 1). Our focal literature source was the international journal Coral Reefs; the world's primary journal for coral reef studies. This journal was specifically selected for its research breadth, while offering the highest concentration of papers on coral reefs. The sole restriction for papers in this journal, apart from scientific merit, is that they pertain to coral reefs; there is no restriction on geographic location or approach (i.e. field or experimental). Limiting our study to this one broad journal therefore minimizes the potential for other biases, associated with journal selection, to confound our results. For each article related to reef fishes published between 1982 and 2018 that involved a field-based component (e.g. fish collection, observation or quantification) $(\mathrm{n}=$ 377 articles) we recorded details pertaining to: a) selected study species, b) the month/s when the field-component of the study occurred, c) fish abundance quantification methods and d) the habitat where and fish quantification methods were performed (studies may involve only some or all of the above; see the supporting information for a full overview of the literature survey and associated methods). It is important to note that our interest is in the selection of study species, locations, methods and times by researchers, i.e. decisions that will fundamentally shape our understanding of these systems. The focus is solely on the decisions made by the scientist(s), not the subsequent popularity or perceived importance of the study based on metrics such as citations or journal impact factor. 


\section{Species biases}

Although biases were recorded in all four study criteria, it was in the selection of focal species that the most striking patterns were revealed. Of an estimated $6000+$ reef fish species, less than 7\% (396 species) were selected for study, with just $0.1 \%$ (6 species) examined 10\% of the time (Fig. S2). Most research is restricted to a small range of quintessential coral reef butterflyfishes and damselfishes. The selection of these specific species may be influenced by a range of factors, however, it is particularly interesting to consider the colouration of these species; almost all focal study species had bright colours, especially yellow (Fig. 2a).

At the broadest scale, looking at all species examined, our results strongly suggest that selected study species are not random with regards to colour (Fig. 2a). Naturally, there is a range of other potential explanations. Yellow fishes may be more territorial and thus easier to observe, see or catch. Most importantly, yellow fish species may be more common or abundant than fishes with other colours. To directly test whether species selection does favor predominantly yellow species, rather than other traits (e.g. territoriality), we looked in detail at the family Pomacentridae. This family was selected as it is, by far, the most frequently studied, making up more than a third of all records. It also contains numerous species, with a wide variety of colour patterns, thus permitting robust analyses. Focusing on the GBR, almost all species had appropriate photographs available. Most importantly, the family is composed of species with very similar traits (other than colour); all have relatively small body sizes, are strongly site attached, show minimal diver avoidance, live in relatively shallow waters, are easily collected and are omnivorous, herbivorous, or planktivorous.

We can therefore ask: compared to the Pomacentridae on the GBR, are study species selected randomly with regards to their colour patterns? The answer is no (Fig. 2b) (see ESM for statistical values). We cannot say species are selected because they are yellow, inferring causation, but we can say with confidence that yellow species are studied most often (and equally, that dark fishes appear to be strongly avoided). Furthermore, if we focus specifically on the abundance of species (around one of the peak research locations in the GBR - Lizard Island); asking if damselfish species are selected randomly with regards to their estimated local abundance, we get the same pattern. Yellow species were preferred, dark ones avoided (Fig. 2c). Taken together, these patterns raise questions about the possibility of a colourbased bias. Interestingly, a recent study using simulated reefscapes provides strong supporting evidence, documenting human preferences for attractive reefs organisms based on colour; with a clear indication that yellow fishes are by far the most attractive (Tribot et al. 2019). Thus, the possibility of yellow fish being both overrepresented and positively selected for based on their colour, represents a distinct possibility.

\section{Methodological biases}

We also found evidence of preference or bias in the three methodological approaches. The relationship between sampling period and time of year was strongly selective, with almost twice the research effort in the summer months (Fig. 3a) (offset in northern and southern hemisphere locations Fig. S1). Likewise, habitats were unevenly studied, with 50\% of all fish censuses undertaken on the reef slope or crest where fish densities and coral cover are often highest (Russ 1984; Wismer et al. 2009); they are therefore, arguably, the most attractive habitats. When examined as a proportion of the available reef area, across four standard reef habitats, this selectivity is striking (Fig. 3b), with $64 \%$ of the censuses looking 
at just $35 \%$ of the reef area. Fish census methods were also revealing (Fig. 3c), with most studies using methods which are likely to have strong diver-effects (potentially missing up to $70 \%$ of fishes) (Dickens et al. 2011; Emslie et al. 2018). Counts from these approaches, therefore, focus on bold, non-diver-averse fishes.

Overall, it appears reef fish studies focus on fishes with bright predominantly yellow hues, using field approaches that focus on relatively warm-water seasons, in attractive locations (that do not represent the majority of reef area), using methods that favor bold fishes. Furthermore, it should be noted that although we looked at four separate aspects, there is a possibility that these factors may be operating synergistically. For example, we may choose locations because they support more bold, yellow fishes or select survey methods that are particularly good at censusing bold (territorial) brightly coloured fishes (cf. Emslie et al. 2018).

\section{Biases and our approach to research}

Biases, be they conscious or sub-conscious may be logical: in summer, reefs are usually warm and calm with high fish recruitment (Meekan et al. 1993; Booth and Beretta 1994). The crest and slope often support the highest densities of fish and corals (Russ 1984; Wismer et al. 2009), and standard fish censuses are quick and easy to conduct. Colour-based biases, however, appear to have a stronger influence from subconscious biases; yellow fishes are undeniably attractive to humans (as reflected by their frequent occurrence on marketing images in magazines) (cf. Tribot et al. 2019), and in reef environments they stand out clearly (Marshall 2000). Unfortunately, whether conscious or subconcious, such selectivity may lead to a biased or partial understanding of coral reef fish ecology.

\section{Why does this matter?}

The problem with subconscious or implicit biases are many fold, with the potential for missed opportunities, partial understanding and misleading interpretations. Indeed, they may lead to an over- or under-estimation of the impacts of climate change or a redirection of research resources to functionally irrelevant species. We provide four examples where biases may change our understanding of reef ecosystems.

Firstly, for example, many of the highly-studied, yellow-hued species have extremely tight associations with live branching coral and may be severely impacted if corals are lost. Indeed, yellow damselfishes (e.g. Pomacentrus moluccensis) and brightly-coloured yellow and white butterflyfishes show some of the strongest declines following coral loss (Pratchett et al. 2006, 2008; Wismer et al. 2019). However, losses in these species may not be representative of other species or families. For example, many dark-coloured damselfishes often show significant increases following bleaching events (Pratchett et al. 2008; Wismer et al. 2019). Our favourite fishes may just be exceptionally sensitive.

Secondly, and by contrast, is the case of the gobies and their allies, collectively termed cryptobenthic reef fishes; one of the most overlooked fish groups on coral reefs (Brandl et al. 2018). Frequently overlooked because of their small size and cryptic behavior, recent work has identified cryptobenthics as a major driver of trophodynamics on coral reefs (Brandl et al. 2019c), supplying up to 70\% of consumed fish flesh (Brandl et al. 2019a).Yet, 
these fishes are strongly selected against in surveys, remaining largely invisible in visual censuses (Ackerman and Bellwood 2000) due to their predominantly drab or cryptic colours (Fig. 1c), and their low densities on the upper reef slope and crest (Depczynski and Bellwood 2005). A similar situation is seen in some off-reef plankton-feeding species, e.g. the fusiliers (Caesionidae), which are often overlooked on visual censuses because they occur high off the reef (Hamner et al. 1988; Russ et al. 2017). Despite being missed, they represent one of the most important conduits for supplying energy to coral reefs via pelagic subsidies (Morais and Bellwood 2019).

Third, is the example of herbivorous reef fishes, a group widely regarded as critically important on coral reefs (Hughes et al. 2010; Bellwood et al. 2019; Brandl et al. 2019b). Even in this group, biases have potentially shaped and/or hindered progress in this field. For example, it was not until detailed video-based assessments of herbivory were conducted that we were able to identify the potential importance of three drab reef fishes Platax pinnatus (Bellwood et al. 2006), Melichthys niger (Tebbett et al. 2020) and Siganus canaliculatus (Fox and Bellwood 2008) in macroalgae removal on coral reefs. Until these video-based studies were performed, the former two species were not recognized as significant reef herbivores in the study areas, while the later had not been recorded from the study location despite the widespread use of traditional census techniques. Thus, highlighting the potential for 'how' we conduct our studies to provide only a partial understanding of specific processes.

Finally, the impacts of biases associated with selective seasonal and location sampling might have a particularly pronounced effect on our understanding of the process of herbivory. This process can be strongly related to seasonally-variable factors such as temperature (Longo et al. 2019). Indeed, evidence suggests that macroalgae removal on GBR reefs can decrease by over $60 \%$ in the winter relative to summer months (Lefèvre and Bellwood 2011), while algal turf consumption by herbivorous fishes in the Caribbean can decrease by over $20 \%$ in the winter (Van Rooij et al. 1998). In addition, while herbivorous fish densities are higher per unit area on the crest and slope (Russ 1984; Wismer et al. 2009), where studies generally count fishes (Fig. 3b), the reef flat is the most substantive reef habitat by total area (Bellwood et al. 2018). Consequently, reef flat habitats support nearly $80 \%$ of the herbivorous fish populations on reefs and account for approximately $75 \%$ of the herbivorous fish biomass production on reefs (Bellwood et al. 2018). Despite this, to-date, we have focused our research on a small subset of the available reef area, providing only a partial view of reef-wide processes. As such, there is a clear potential to underestimate or overestimate the rates of specific functions depending on 'when' and 'where' we perform our studies.

Many of the examples above stand in marked contrast to the overwhelming attention paid to damselfishes and butterflyfishes, with $>35 \%$ and $>11 \%$ of all studies that selected species involving these families, respectively (compared to $<7 \%$ and $<2 \%$ of studies involving the cryptobenthic gobies or blennies, respectively, and $<1 \%$ involving the off-reef fusiliers). Arguably, damselfishes and butterflyfishes are among the most intensely studied reef fish families. However, their sensitivity to coral loss (Pratchett et al. 2006, 2008) offers a stark contrast to the patterns seen in the examples where herbivores, cryptobenthics and offreef planktivores show an unexpected degree of resilience, especially in supporting ecosystem processes, even in the face of coral loss (Morais and Bellwood 2019; Robinson et al. 2019; Taylor et al. 2019). Unfortunately, it is fishes such as damselfishes and butterflyfishes that are often used to examine the impacts of future climate change scenarios, habitat degradation and predator-prey interactions; potentially biasing our view towards one of high-sensitivity (cf. Clark et al. 2020). Much of the research to-date appears to be looking 
at the 'passengers' rather than the 'drivers' of ecosystems (sensu Walker 1992); many of which are evolutionary baubles on the tree of life (sensu Bellwood et al. 2017). This results in a partial understanding of reef ecosystems. Previous results, therefore, are not wrong, just incomplete. The most valuable step is in recognizing the potential for such oversights. Thus, the selection of study species, as well as when, where and how we conduct our research, has the potential to profoundly change our perception of coral reef ecosystems and associated critical processes.

\section{Conclusions}

As coral reefs reconfigure in response to anthropogenic stressors, it is becoming

\section{Acknowledgements}

We thank three anonymous reviewers for insightful comments and the Australian Research Council (DRB; grant number CE140100020 and FL190100062) for financial support. increasingly clear that we need to understand what keeps reefs functioning if we are to steer them through the challenges they will face in the near future (Hughes et al. 2017; Bellwood et al. 2019). Yet, it appears that other factors, not necessarily functional importance, may have largely influenced our selection of study species, and when, where and how we have studied them. These factors, potentially shaped by human preferences or biases, may have limited our ability to fully understand reef functions.

If we are to understand high-diversity ecosystems, be they coral reefs, alpine grasslands or rainforests, it is imperative to understand ourselves first. There is undoubtedly a place for interest-based science looking at morphologically unique or colourful species. But in a rapidly changing world where the functionality of high-diversity ecosystems is under threat, a new focus on function rather than convenience or appearance may be warranted (Bellwood et al. 2019). Brightly coloured fishes may be interesting, but the future of coral reefs may depend on their drab counterparts that do not make it into advertisements but do keep coral reefs alive.

\section{References}

Ackerman JL, Bellwood DR (2000) Reef fish assemblages: A re-evaluation using enclosed rotenone stations. Mar Ecol Prog Ser 206:227-237

Asplund M, Welle CG (2018) Advancing science: how bias holds us back. Neuron 99:635639

Barlow J, França F, Gardner TA, Hicks CC, Lennox GD, Berenguer E, Castello L, Economo EP, Ferreira J, Guénard B, Leal CG, Isaac V, Lees AC, Parr CL, Wilson SK, Young PJ, Graham NAJ (2018) The future of hyperdiverse tropical ecosystems. Nature 559:517526

Baum JK, Martin TG (2018) It is time to overcome unconscious bias in ecology. Nat Ecol Evol 2:201 
Bellwood DR, Goatley CHR, Bellwood O (2017) The evolution of fishes and corals on reefs: form, function and interdependence. Biol Rev 92:878-901

Bellwood DR, Hughes TP, Hoey AS (2006) Sleeping functional group drives coral-reef recovery. Curr Biol 16:2434-2439

Bellwood DR, Streit RP, Brandl SJ, Tebbett SB (2019) The meaning of the term 'function' in ecology: a coral reef perspective. Funct Ecol 33:948-961

Bellwood DR, Tebbett SB, Bellwood O, Mihalitsis M, Morais RA, Streit RP, Fulton CJ (2018) The role of the reef flat in coral reef trophodynamics: past, present, and future. Ecol Evol 8:4108-4119

Bonnet X, Shine R, Lourdais O (2002) Taxonomic chauvinism. Trends Ecol Evol 17:1-3

Booth DJ, Beretta GA (1994) Seasonal recruitment, habitat associations and survival of pomacentrid reef fish in the US Virgin Islands. Coral Reefs 13:81-89

Bornmann L, Mutz R, Daniel H-D (2007) Gender differences in grant peer review: a metaanalysis. J Informetr 1:226-238

Brandl SJ, Goatley CHR, Bellwood DR, Tornabene L (2018) The hidden half: ecology and evolution of cryptobenthic fishes on coral reefs. Biol Rev 93:1846-1873

Brandl SJ, Morais RA, Casey JM, Parravicini V, Tornabene L, Goatley CHR, Côté IM, Baldwin CC, Schiettekatte NMD, Bellwood DR (2019a) Response to comment on "demographic dynamics of the smallest marine vertebrates fuel coral reef ecosystem functioning." Science 366:eaaz1301

Brandl SJ, Rasher DB, Côté IM, Casey JM, Darling ES, Lefcheck JS, Duffy JE (2019b) Coral reef ecosystem functioning: eight core processes and the role of biodiversity. Front Ecol Environ 17:445-454

Brandl SJ, Tornabene L, Goatley CHR, Casey JM, Morais RA, Côté IM, Baldwin CC, Parravicini V, Schiettekatte NMD, Bellwood DR (2019c) Demographic dynamics of the smallest marine vertebrates fuel coral-reef ecosystem functioning. Science 364:11891192

Clark JA, May RM (2002) Taxonomic bias in conservation research. Science 297:191-192

Clark TD, Raby GD, Roche DG, Binning SA, Speers-roesch B, Jutfelt F, Sundin J (2020) Ocean acidification does not impair the behaviour of coral reef fishes. Nature 577:370375

Depczynski M, Bellwood DR (2005) Wave energy and spatial variability in community structure of small cryptic coral reef fishes. Mar Ecol Ser 303:283-293

Dickens LC, Goatley CHR, Tanner JK, Bellwood DR (2011) Quantifying relative diver effects in underwater visual censuses. PLoS One 6:e18965

Emslie MJ, Cheal AJ, MacNeil MA, Miller IR, Sweatman HPA (2018) Reef fish communities are spooked by scuba surveys and may take hours to recover. PeerJ 6:e4886

Fox RJ, Bellwood DR (2008) Remote video bioassays reveal the potential feeding impact of the rabbitfish Siganus canaliculatus (f: Siganidae) on an inner-shelf reef of the Great Barrier Reef. Coral Reefs 27:605-615 
França FM, Benkwitt CE, Peralta G, Robinson JPW, Graham NAJ, Tylianakis JM, Berenguer E, Lees AC, Ferreira J, Louzada J, Barlow J (2020) Climatic and local stressor interactions threaten tropical forests and coral reefs. Philos Trans R Soc B Biol Sci 375:20190116

Hamner WM, Jones MS, Carleton JH, Hauri IR, Williams DM (1988) Zooplankton, planktivorous fish, and water currents on a windward reef face: Great Barrier Reef, Australia. Bull Mar Sci 42:459-479

Hughes TP, Barnes ML, Bellwood DR, Cinner JE, Cumming GS, Jackson JBC, Kleypas J, Leemput IA van de, Lough JM, Morrison TH, Palumbi SR, Nes EH Van, Scheffer M (2017) Coral reefs in the Anthropocene. Nature 546:82-90

Hughes TP, Graham NAJ, Jackson JBC, Mumby PJ, Steneck RS (2010) Rising to the challenge of sustaining coral reef resilience. Trends Ecol Evol 25:633-642

Knezek P (2017) Implicit bias in astronomy. Nat Astron 1:0151

Lefèvre CD, Bellwood DR (2011) Temporal variation in coral reef ecosystem processes: herbivory of macroalgae by fishes. Mar Ecol Prog Ser 422:239-251

Longo GO, Hay ME, Ferreira CEL, Floeter SR (2019) Trophic interactions across 61 degrees of latitude in the Western Atlantic. Glob Ecol Biogeogr 28:107-117

Marshall NJ (2000) Communication and camouflage with the same "bright" colours in reef fishes. Philos Trans R Soc Lond B Biol Sci 355:1243-1248

McNutt M (2016) Implicit bias. Science 352:1035-

Meekan MG, Miliciche MJ, Doherty PJ (1993) Larval production drives temporal patterns of larval supply and recruitment of a coral reef damselfish. Mar Ecol Prog Ser 93:217-225

Morais RA, Bellwood DR (2019) Pelagic subsidies underpin fish productivity on a degraded coral reef. Curr Biol 29:1521-1527

Moss-Racusin CA, Dovidio JF, Brescoll VL, Graham MJ, Handelsman J (2012) Science faculty's subtle gender biases favor male students. Proc Natl Acad Sci 109:16474-16479

Pratchett MS, Munday PL, Wilson SK, Graham NAJ, Cinner JE, Bellwood DR, Jones GP, Polunin NVC, McClanahan TR (2008) Effects of climate-induced coral bleaching on coral-reef fishes - Ecological and economic consequences. Oceanogr Mar Biol An Annu Rev 46:251-296

Pratchett MS, Wilson SK, Baird AH (2006) Declines in the abundance of Chaetodon butterflyfishes following extensive coral depletion. J Fish Biol 69:1269-1280

Robinson JPW, Wilson SK, Robinson J, Gerry C, Lucas J, Assan C, Govinden R, Jennings S, Graham NAJ (2019) Productive instability of coral reef fisheries after climate-driven regime shifts. Nat Ecol Evol 3:183-190

Van Rooij J, Videler J, Bruggemann J (1998) High biomass and production but low energy transfer efficiency of Caribbean parrotfish : implications for trophic models of coral reefs. J Fish Biol 53:154-178

Russ GR (1984) Distribution and abundance of herbivorous grazing fishes in the central Great Barrier Reef. II. Patterns of zonation of mid-shelf and outershelf reefs. Mar Ecol Prog Ser 20:35-44 
Russ GR, Aller-rojas OD, Rizzari JR, Alcala AC (2017) Off-reef planktivorous reef fishes respond positively to decadal-scale no-take marine reserve protection and negatively to benthic habitat change. Mar Ecol 38:e12442

Taylor BM, Benkwitt CE, Choat H, Clements KD, Graham NAJ, Meekan MG (2019) Synchronous biological feedbacks in parrotfishes associated with pantropical coral bleaching. Glob Chang Biol 26:1285-1294

Tebbett SB, Hoey AS, Depczynski M, Wismer S, Bellwood DR (2020) Macroalgae removal on coral reefs: realised ecosystem functions transcend biogeographic locations. Coral Reefs 39:203-214

Tribot A, Deter J, Claverie T, Guillhaumon F, Villéger S, Mouquet N (2019) Species diversity and composition drive the aesthetic value of coral reef fish assemblages. Biol Lett 15:20190703

Walker BH (1992) Biodiversity and ecological redundancy. Conserv Biol 6:18-23

Wenneras C, Wold A (1997) Nepotism and sexism in peer-review. Nature 387:341-343

Wismer S, Hoey AS, Bellwood DR (2009) Cross-shelf benthic community structure on the Great Barrier Reef: relationships between macroalgal cover and herbivore biomass. Mar Ecol Prog Ser 376:45-54

Wismer S, Tebbett SB, Streit RP, Bellwood DR (2019) Spatial mismatch in fish and coral loss following 2016 mass coral bleaching. Sci Total Environ 650:1487-1498 

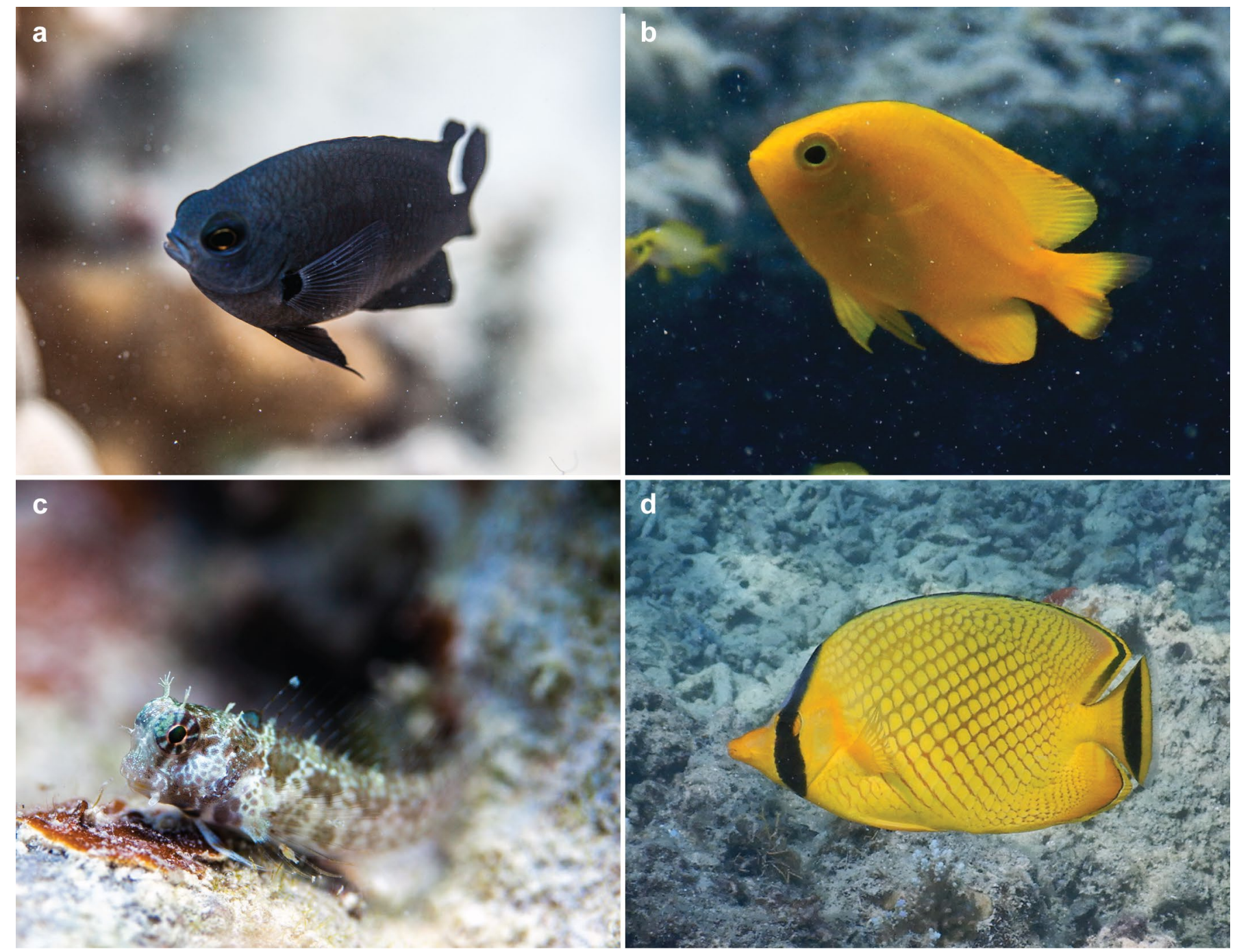

Figure 1 Four coral reef fish species; a) Pomacentrus brachialis, b) Pomacentrus moluccensis, c) Crossosalarias macrospilus and d) Chaetodon rafflesii. Of these species, two have characteristics that would lead to strong positive selection as study species (b, d), while two $(\mathrm{a}, \mathrm{c})$ are rarely studied. (Photos. a, c Victor Huertas, b. Christopher Hemingson, d.

371 Renato Morais). 

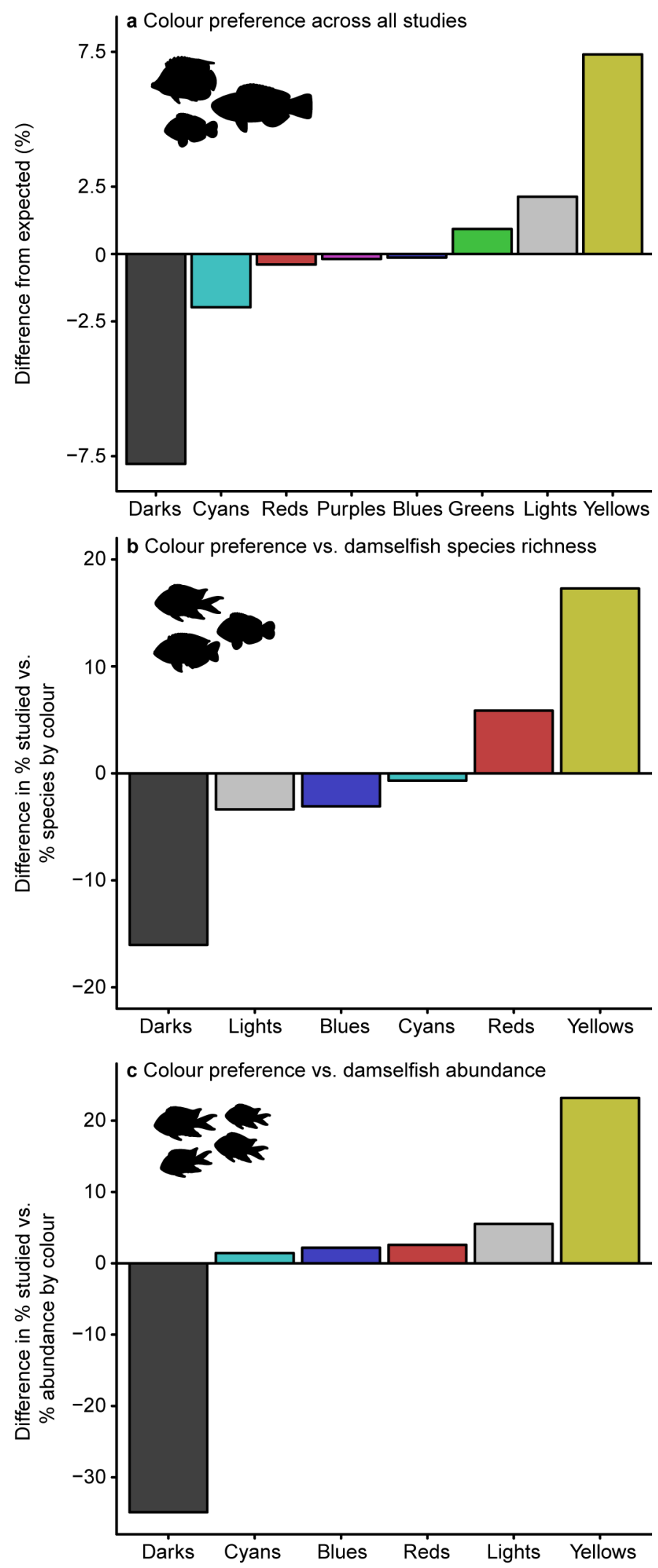

Figure 2 Species selection in coral reef fish research (based on 37 years of research in the 374 journal Coral Reefs). Whether examining species colouration relative to a) all species studied, 375 b) all damselfish species on the GBR, or c) damselfish abundances on GBR mid-shelf reefs, 376 the pattern was the same: research was overwhelmingly focused on yellow fishes with a 377 strong negative selection for dark-coloured fishes. 

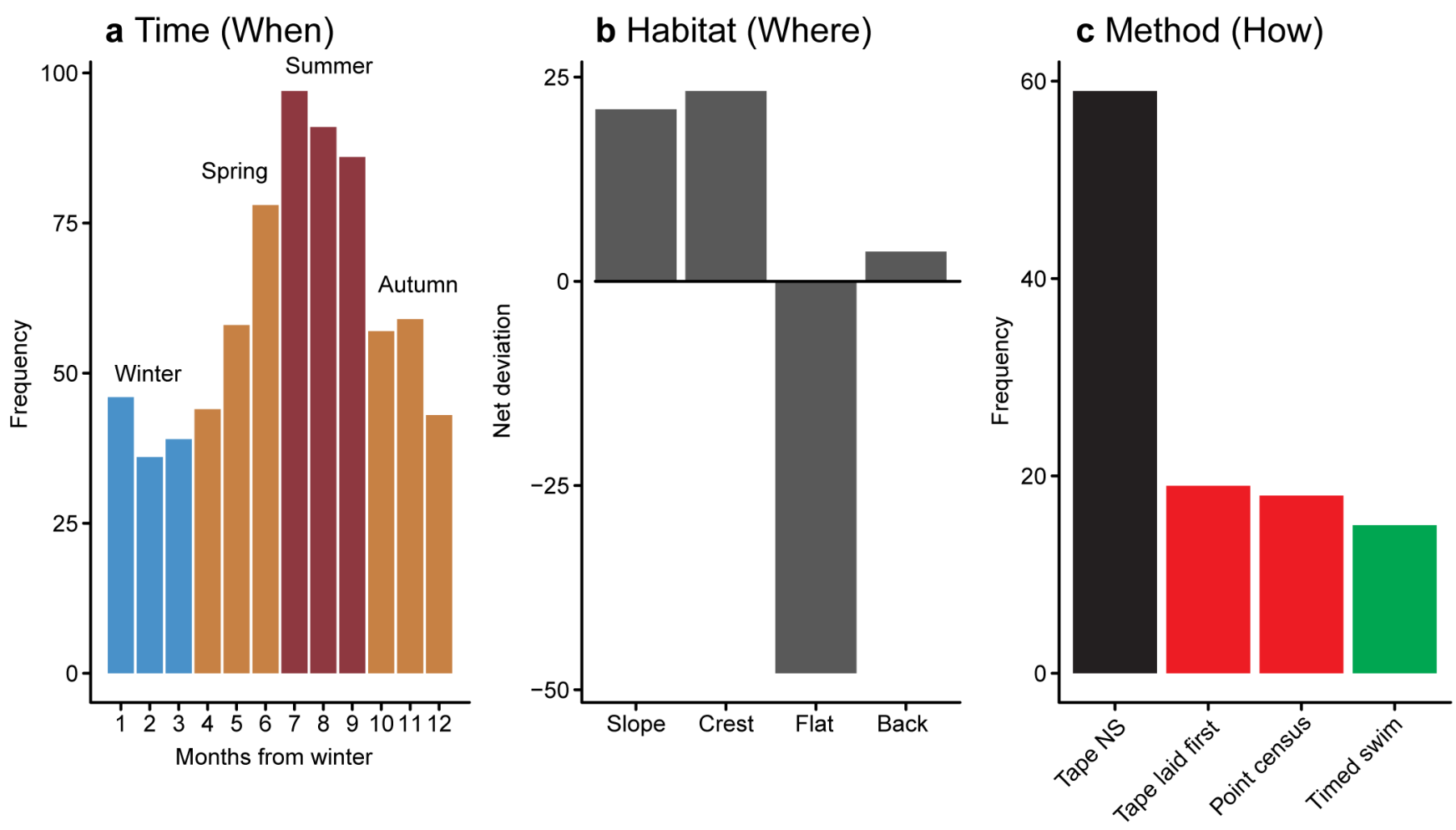

Figure 3 The when, where and how of coral reef fish research. a) Frequency distribution of sampling months during field-based studies (standardized for the northern and southern hemisphere as months since first winter month). b) The selectivity of four major reef habitats as fish census locations (deviation from expected if habitats were selected based on their area covered). c) The frequency distribution of the four most common fish census methods (NS = not specified). For more details please see the supporting information. 